\title{
Vulnerability to flood risks in Japanese urban areas: crisis management and emergency response for efficient evacuation management
}

\author{
M. Thomas \& T. Tsujimoto \\ Nagoya University, Department of Civil Engineering, Japan
}

\begin{abstract}
Today, flood risk in Japan occurs mainly in high density populated areas, as a consequence of the rapid urban development of the deltaic plains of Japan during the second half of the $20^{\text {th }}$ century. At the end of the $20^{\text {th }}$ century risk management began to shift from mainly structural management to a more "integrated" management. The evacuation process is one of the factors revealing this shift. In Nagoya the evacuation process enhancement started with the Tokai flood disaster (September 2000) and continues to this day. The most recent flood events (urban flood of 2008 and typhoon No. 14 of 2011) highlight, however, how the crisis management can still be vulnerable regarding evacuation. Our research intends to assess the vulnerability factors of the crisis management system, and especially of the evacuation process through interviews and a questionnaire analysis method, in order to propose an integrated way of dealing with evacuation in the case of a flood, imputing on GIS geographical as well as social characteristics and evacuation patterns. Our research shows that the evacuation process is effective despite low evacuation rate during past flood event. In that regard improving the evacuation process cannot be separated from the improvement of informational tools, but it can be seen that the possession of hazard maps have few impact on evacuation decision. The efficiency of the evacuation process in the case of a small to moderate flood event could therefore be enhanced as the large-scale evacuation broadcast tends to target a population in which more than half of the people do not need to evacuate. In the case of a small flood event those repeated evacuation demands can increase a relatively false sense of security and a loss of interest to flooding in general.

Keywords: vulnerability, adaptive capacity, floods, evacuation, GIS, Japan.
\end{abstract}




\section{Introduction}

With its three biggest cities located in deltaic fluvial plains, Japan is at a high flood risk. In Japanese megacities, although innovative and efficient measures have been taken, the flood risk remains, and the vulnerability to flood risk is expected to increase with the combination of natural factors characterizing the hazards (expected and unexpected effects of climate change), territorial factors (settlements of stakes in lowlands area, apparition of "new" urban-type floods), and societal factors (knowledge and acceptance of flood risk, willingness to evacuate).

As the flood risk is changing, so is its management, and on concentrating our research on the evacuation process the purpose of this paper is to define small scale vulnerability of dwellings and its relationship to the evacuation management at city and prefectural scale. Through the changes in flood risk management since the disaster of the 11 and $12^{\text {th }}$ September 2000 in Nagoya-city will be analysed the vulnerability and adaptive capacity concepts to flood risks in flood risk management, from risk actors standpoint and GIS mapping.

\section{Theoretical framework for multi-scale vulnerability analysis}

\subsection{Vulnerability and adaptive capacity concepts: towards integrated system management}

The concept of vulnerability is one of the numerous tools that can be used in risk analysis. It has been described as the flip-side of the resilience concept [1] and of the robustness concept $[1,3]$, as it is described in broad terms as "the susceptibility to be harmed" [4]. The resilience is described as "the ability of a system to absorb shocks, to avoid crossing a threshold into an alternate and possibly irreversible new state, and to regenerate after disturbance" [5], and the robustness concept as "a systems ability to remain functioning under disturbances" [3]. But if the vulnerability has not always the positive aspect of the here above two concepts, it consists in a helpful analysis tool when confronted to the evaluation of a system's evolution, as it can be considered as "the potential for a change or transformation of the system when confronted with a perturbation, rather than the outcome of this confrontation" [2].

The use of the vulnerability concept in risks studies has been used in two related and complementary approaches. The first, classic (end of 1970s) approach consisted of measuring the potential exposure of the different stakes in a system [6]. In this case, the evaluation of the vulnerability is made through the exposure as an attribute of the relationship between the system and the perturbation [2]. It corresponds to a technical and effective management of disasters, which could be summed as the following non mathematical equation:

$$
\text { Hazard } \times \text { vulnerability }(\text { exposure })=\operatorname{risk}[7,8]
$$


The second approach, enriched by research on natural hazards $[9,10]$, helped to understand how the vulnerability concept cannot be taken outside of the system it's related to. The vulnerability being the propriety of a system, evolving as the system evolves, and can be revealed during an event, or a disaster. A key-component to the vulnerability concept is the "adaptive capacity" concept, "the flexibility of ecosystems, and the ability of social systems to learn in response to disturbances" $[11,12]$.

Because the flood risk management in Nagoya these last years knew noticeable transformations, the vulnerability as propriety of a system increasing this system to be harmed in case of a perturbation, as well as the concept of adaptive capacity as formulated hereinabove by Turner et al. [12] will be used to analyse the ability of the flood risk Japanese management system to evolve during the past years and the influence of this evolution on the evacuation process in Nagoya-city.

\subsection{Vulnerability and adaptive capacity model}

In order to build an efficient risk management, aside from the adaptive capacity is also needed, and is paired with it, the ability to build efficient risk governance. It has been made clear in natural hazards and in climate change research that vulnerability is the propriety of a system. Megacities are a good example of complexes, human-made, multi-level chain reactions, highly vulnerable type of systems. Flood risk management in such systems needs the collaboration of very different actors, with purposes and focuses that may differ. This is why it is needed to take into account risk governance in the risk management system vulnerability and adaptive capacity factors.

Building risk governance can be summarized in collecting, analysing and communicating relevant risk information (through a complex web of actors, rules, conventions, processes and mechanisms), taking risk management decisions at the right time, and for those information and decisions to be understood by the public concerned [13]. Although a difference has to be made between risk management and risk governance. The definitions for risk management are scarce, and can have different meanings, from risk response - the risk management being the management of the crisis to which the actors are confronted [14] - to the management of the risk at all times of the risk (mitigation, preparedness, response and recovery [15]). Will be considered here that risk governance is part of the risk management system, which entails the different actors, the actions they decide to setup (hardware and software measures), and the concrete results in the risk system and the consequences those measures will have. Risk governance would be then the central part of the risk management.

Building an efficient risk governance, to go further, includes the idea brought up by the studies on climate change that risks in general have to be thought as long-term duration processes. Adger [16] made a clear differentiation between effectiveness and efficiency in adaptability capacity. The purpose of effectiveness consists in responding to objectives that have been fixed, in reducing the impacts of hazards and exposure, or to reduce the risk and avoid the 
danger (in case of floods, building levees or flood-controlling dams are considered as effective measures). An effective risk management reduces therefore the vulnerability to a certain type of flood risk, at a certain time. An efficient adaptability capability has to take into account, in every measure considered, not only the effectiveness at a point in time and space, but also on long-term and at wide-range scale. It consists most of the time in an economic analysis, but also to the evaluation of the cost-benefit brought by the changes to come that cannot be calculated, and on the timing on the adaptation action. Effective risk governance, leading to an effective risk management, will have immediate visible and invisible results in the adaptation capacity (dike reinforcement). An efficient one will try to take into account the long-term effect and the different outcomes of these measures (loss of landscape, oblivion of the flood risk to riverine population etc.).

For the vulnerability to be durably reduced, and for the adaptive capacity to be efficient on long-term management, efficient risk governance and therefore risk management is needed.

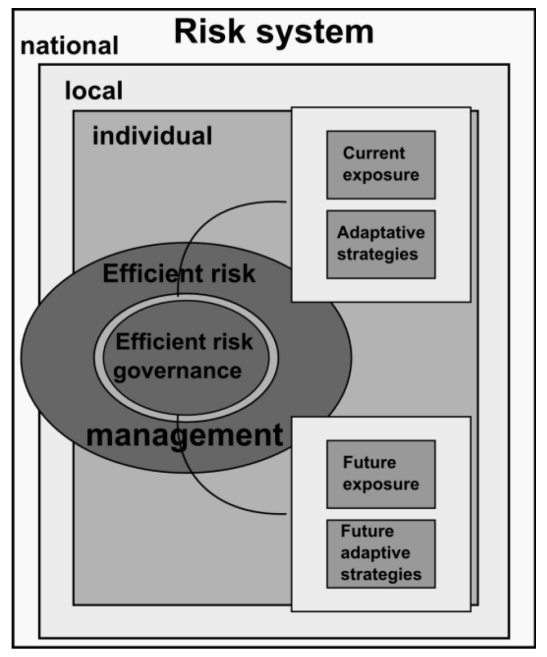

Figure 1: Vulnerability assessment model (from Smit and Wandel [17]).

\section{Methodology}

\subsection{Study area}

In order to analyse the vulnerability and adaptive capacity of megacities in Japan, it is easier to compare the risk management at two stages, preferably before and after a memorable event. The event doesn't have to be a disaster per say, however the disastrous events give the opportunity to reveal vulnerability as well as adaptive capacity, and therefore Nagoya-city and the 2000 Tokai flood disaster were chosen as the starting point of a multi-scale vulnerability and adaptive capacity analysis. 
Nagoya-city is the $4^{\text {th }}$ largest Japanese city in Japan, with a total population of $2,272,075$ [18] on the $1^{\text {st }}$ of January 2014. Floods in Nagoya-city are not an unknown event, the main water-related disasters that happened during the past 70 years were the Ise-bay typhoon of 1959, the flood of 2000 (called Tokai flood) and the 2008 urban flood. The Tokai flood occurred on September 11 and 12 , and damaged part of the Tokai region, due to heavy rainfall, amounting up to a total of $567 \mathrm{~mm}$ (one third of the average annual rainfall). The Shin River and Tenpaku River suffered levee breaches, the Shonai River and Yahagi River flooded by levee overtopping, and the rainfall accumulating near the levees could not be evacuated due to lack of drainage ability $[19,20]$. The total loss for the Tokai region reached the amount of 978.3 billions of yen, 155 injured people and 10 fatalities for the Tokai region, and $37 \%$ of Nagoya-city urban territory flooded, 45 injured and 4 fatalities.

\subsection{Interviews analysis grid}

Between the $01 / 04 / 2012$ to the $01 / 11 / 2012$ exploratory semi-conductive interviews to 32 risk managers were conducted (from State actors level to local disaster manager actors) for Nagoya-city, and 13 individuals either living in risky areas or having experienced the Tokai flood in September 2000.

As it is shown in table 1, the purpose of those interviews was in a first time to setup the different factors of vulnerability and adaptive capacity. As for the risk governance, being part of the risk management system and a condition to the reduction of the vulnerability, it was set aside in a third category. In a second time were interrogated the different factors of vulnerability, adaptive capacity and the risk governance status through the effectiveness and efficiency concepts.

\subsection{GIS small scale evacuation vulnerability}

The interviews to the risk managers confirmed by a survey analysis realized in 2011 by Aichi prefecture [21] pointed out the actual problem of the evacuation process in case of floods, (details in next section). The interviews to the population helped understand the reasons why one would hesitate to evacuate despite the evacuation recommendation, but did not help to understand how much and in what measure the residents in risky area are vulnerable. Moreover, neither of the interview methodology gave a clear understanding of the small-scale vulnerability to evacuation.

The type of building and their vulnerability factors have been input (number of floors, housing embankment) on GIS, crossed with information available for the public, the Nagoya Hazard Maps and the three types of expected floods: major flood from national class river, medium flood from prefectural class river and small urban flood.

A total of 961 building were referenced in three city-blocks of the Nishi ward in Nagoya-city (Komoharachou, Ashiharachou and Nakaotaisanchoume), the field has been chosen for being in risky area, and having suffered from the Tokai flood in 2000 . 
Table 1: Effectiveness and efficiency in risk management for evacuation interview analysis grid.

\begin{tabular}{|c|c|c|c|}
\hline & \multicolumn{2}{|l|}{ INTERVIEWS } \\
\hline & & To official risk managers & To population \\
\hline \multirow{9}{*}{$\begin{array}{l}\text { Effectiveness } \\
\text { efficiency }\end{array}$} & \multirow{3}{*}{$\begin{array}{l}\text { Vulnerability } \\
\text { factors }\end{array}$} & Software measures setup & $\begin{array}{l}\text { Last emergency evacuation } \\
\text { lived }\end{array}$ \\
\hline & & Hardware measures setup & $\begin{array}{l}\text { Willingness to evacuate } \\
\text { in the future }\end{array}$ \\
\hline & & & Risk knowledge \\
\hline & \multirow{3}{*}{$\begin{array}{l}\text { Adaptive capacity } \\
\text { factors }\end{array}$} & $\begin{array}{l}\text { Changes in the flood risk } \\
\text { protection }\end{array}$ & $\begin{array}{l}\text { Enhancements to } \\
\text { housing after } 2000\end{array}$ \\
\hline & & \begin{tabular}{|l|} 
Principal changes after \\
2000
\end{tabular} & Emergency supplies \\
\hline & & $\begin{array}{l}\text { Main objectives of the } \\
\text { flood risk management } \\
\text { today }\end{array}$ & $\begin{array}{l}\text { Increase of the interest in } \\
\text { risk management } \\
\text { willingness to know } \\
\text { more about floods }\end{array}$ \\
\hline & \multirow{3}{*}{ Risk governance } & Actors in touch with & $\begin{array}{l}\text { Access to different data and } \\
\text { understanding data }\end{array}$ \\
\hline & & $\begin{array}{l}\text { Actors of the risk } \\
\text { management } \\
\text { communication }\end{array}$ & $\begin{array}{l}\text { Understanding } \\
\text { communicated data }\end{array}$ \\
\hline & & $\begin{array}{l}\text { Personal goals and their } \\
\text { integration to the risk } \\
\text { management system's } \\
\text { understanding }\end{array}$ & \\
\hline
\end{tabular}

\section{Results}

\subsection{Risk management and adaptive capacity}

It has to be pointed out that despite the amount of physical damages the human damages during the Tokai flood in 2000 were low. The risk managing system succeeded in an emergency evacuation of more than 5,500,000 people [19], despite the absence of official evacuation process at that time. Evacuation was difficult because it happened as an emergency measure after levees on Shin River breached and most of the people had to evacuate while the water level was high, but considered all in all successful. The Tokai flood marked for Nagoya the starting point of the creation of evacuation process measure. The evacuation process measure gathered old risk management actors: the national River Bureau 
and municipal disaster prevention actors through the implementation of "watch", "danger", and "evacuation" water level thresholds for a quicker and better management, and new actors: media companies in charge of warning the population of evacuation recommendation through cellular phones, radio, and television. The Hazard Maps released in 2001 and revised in 2010, are sent directly to the population and downloadable from the city mayor office [18]. Local disaster management bureau created maps of damages at the ward level, to increase their local knowledge of risky areas, and some of them enhanced flood risk knowledge through reunions and seminars on flood risk. Hardware measures have been enhanced the year following the disaster, and were finished in 2005. In 2011 during an event with a similar hazard to the Tokai flood, it has been demonstrated that the hardware measures setup between 2001 and 2006 were effectively containing the hazard. However, at that time, communication misunderstandings between old and new actors of the evacuation management lead to the evacuation recommendation for one million persons, thus exceeding by far the actual need for evacuation for this event.

\subsection{Evacuation as a vulnerability factor for population?}

It has been difficult to find persons willing to talk about flood disaster and evacuation processes. As a consequence, the data collected during the interviews to the population were analyzed in comparison with the survey for evacuation in case of flood realized by Aichi prefecture in December 2011 (3 months after the 2011 flood event).

When interrogated about the risk culture, most of the interviewees answer knowing the major past flood disasters (Ise-bay typhoon and Tokai flood), but also the small event of the precedent year. The same findings have been found by the Aichi prefecture survey, although during the interviews it was obvious that resident who experienced the Tokai flood were reluctant to refer to it when asked about floods (flood risk is accepted, but with limits). The risk culture is also enhanced by the preparation (survival kits, knowledge of safe areas and risky areas) to more general type of disasters (earthquakes).

The Tokai flood seems to be remembered by the people who lived in flooded areas in 2000. It is not described as a shock, although the experiences related clearly showed that the experience was not pleasant: car stuck in the high water or because of the traffic, and impossibility to move, doubt about what to do and where to go when the water reached the house... The rare persons talking about the flood without referring to unpleasant experience were two people who stayed at home "because I knew it to be safe". The levee breaches especially seem to remain a shocking enough event to be considered in the survey [21] a risk more important than other flooding types. The trust bestowed upon authorities was not a subject broached during the interviews. Most of the interviewed people seemed to have high confidence in structural measures realized after 2000, but somehow did not seem to be interested in evacuation warnings (most of the time "my house if safe" was the main reason called upon). Comparing these results with the 2011 Aichi prefecture survey, it seems that the trust in authorities is high (expectation for government and the local residents association to improve the 
disaster prevention effectiveness and the information delivery), and so is the current medium chosen to deliver information (television, radio). Although if the distributed hazard maps seems to be for the population, a valid teaching material in their opinion, only $15 \%$ of the surveyed population responded that they read and understood it.

\subsection{Exposure to flood risk and needed evacuation}

Comparing the empirical data gathered during on the field and the statistical data available for housing and households from Nagoya office, an error of 268 apartments (18\% of all the 1424 apartments evaluated) have been noticed and will be taken into account when evaluating the number of households and persons in need of an evacuation for the three reference model floods. The number of family members living in one household will also be considered. The Komoharachou district being more an industrial type of district, the average family members for a household is 1.7 whereas in the two other districts, it reaches 2.5 .

The repartition between housing and non-housing buildings is close to equal ( $46.5 \%$ non-housing building for $56.5 \%$ building housing). Repartition of evaluated population by building class is however very differentiated (figures 2 and 3 and table 2).

Depending on the hazard type the rate of persons that need evacuation differs, knowing that most of the people living in risky areas live in high condominiums $(63 \%)$ they are therefore not in grave danger in case of a flood disaster, and a large amount of persons do not need to evacuate, even if the more vulnerable private two-stories house type is the most common. For Shonai River model flooding $41 \%$ of the population evaluated would need to evacuate, $39 \%$ for a Shin River model flood, and $0.8 \%$ on case of urban flooding.

In order to represent population need of evacuation in case of flood, maps have been realized, to help understand patterns in housing vulnerabilities. The repartition of housing is however too homogenous in these districts to notice patterns.

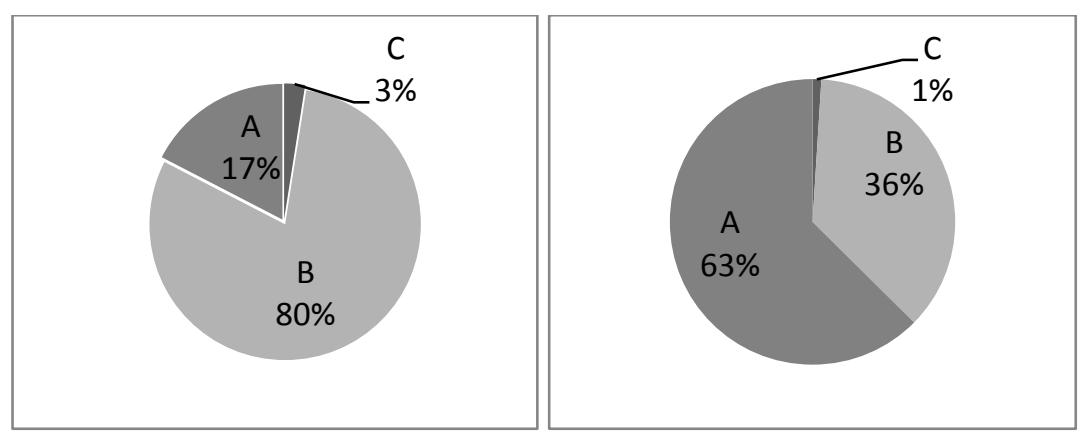

Figure 2: Left: Housing type repartition $(\mathrm{C}=1$ floor, $\mathrm{B}=2$ floors, $\mathrm{A}=3$ floors and more); Right: Apartments repartition by housing type. 

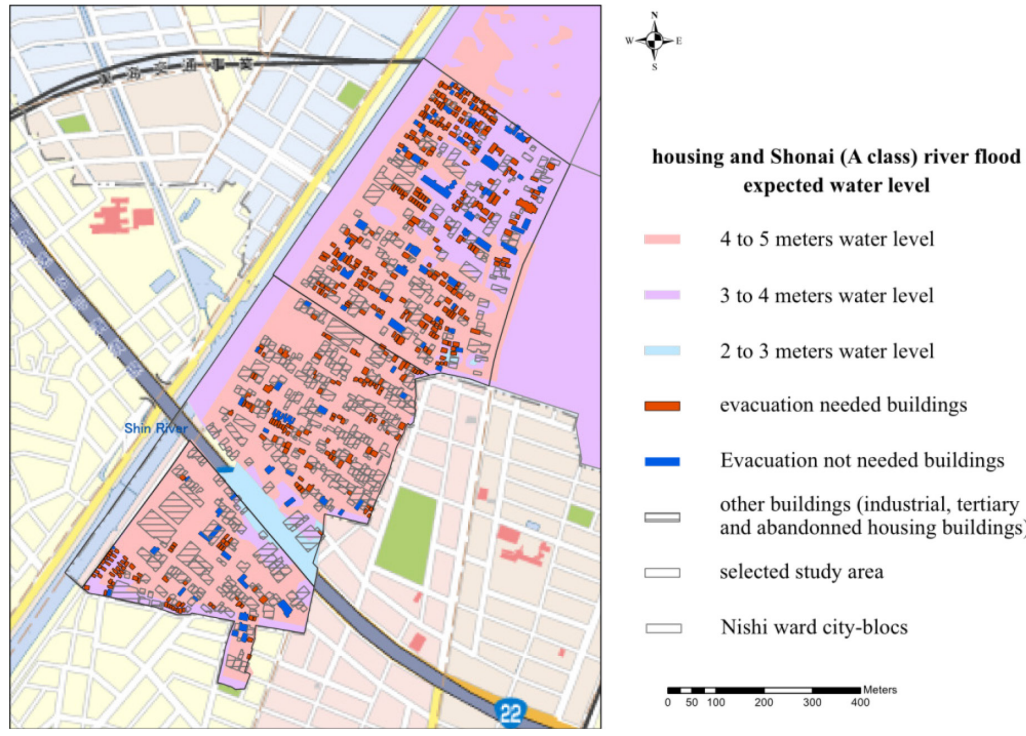

Figure 3: Housing evacuation needed for Shonai River model flood.

Table 2: Evacuation needed evaluation.

\begin{tabular}{|l|r|r|r|r|}
\hline & \multicolumn{1}{|l|}{$\begin{array}{l}\text { Shonai } \\
\text { flood }\end{array}$} & \multicolumn{1}{l|l}{$\begin{array}{l}\text { Shin } \\
\text { flood }\end{array}$} & \multicolumn{1}{l|}{$\begin{array}{l}\text { Urban } \\
\text { flood }\end{array}$} & \multicolumn{1}{l|}{$\begin{array}{l}\text { Total } \\
\text { population }\end{array}$} \\
\hline evacuation & 1030 & 976 & 20 & 2499 \\
\hline no evacuation & 1580 & 1583 & 2139 & 2499 \\
\hline
\end{tabular}

\section{Discussion}

Adaptive capacity is one of the strong points of the risk management in Nagoyacity. Confronted to a new kind of disaster, the risk management system respond quickly and effectively (has been seen in 2000, and 2008) to new kind of hazards, and new kind of disasters. The lessons learned from the past, and different disasters are also observable (1995 Kobe earthquake), making the flood risk management system flexible. This adaptive capacity allows the flood risk management to evolve and to integrate new actors, and new purposes, building therefore better risk governance.

The interviews to the population revealed less clear adaptive capacity, and more potential vulnerability to flood in the fact that it is difficult to evaluate the number of persons willing to evacuate in case of a disaster. From the population standpoint, it was also difficult to evaluate their perception of the risk management and how they were integrated in it, as the answer both to the interviews and the survey [21] were unclear. It can be said, though, that the acceptance of the flood risk might be high, and the preparedness good, demonstrating a good adaptive capacity. The acceptance of a flood disaster is 
very much less clear, as is the acceptance of an unnecessary evacuation warning. Therefore it was found the need to evaluate the actual necessity for evacuation in case of a flood disaster like the Tokai flood.

From the GIS data gathered, the difference of people asked to evacuate in case of a flood warning and evacuation recommendation might be high. As said previously, more than one million people were asked to evacuate during the last event in 2012, due to a lack of understanding between old actors and new actors of the risk management. But even so, in one city-block and for the worst-case river flood scenario, $41 \%$ of the population should evacuate to be safe, and in the least dangerous case $0.8 \%$. If broad evacuation recommendation is effective in a short-term goal, it may be not as efficient as wanted to answer to long-term goals.

\section{Conclusion}

Japanese flood management system in Nagoya-city has changed during these past years, demonstrating a high adaptive capacity to new challenges flood risk poses in megacities today. New flood risks appeared; they are caused by more intensive hazards or generated by urban shape. The risk management aims and succeeds in improving structural measures, developing software measures through the integration of new actors, developing a more integrated management and therefore better risk governance for flood risks. In that regard, the flood risk vulnerability can be considered low, and the system aiming for efficiency. The low evacuation rates for the last flood events seem to better correspond to effectiveness achievement goal. Efficiency in evacuation procedures would be better achieved with a clear understanding for the population of the received information, making it easier for them to make a choice when confronted to a disaster. On that matter, risk governance still has progress to do, despite the high adaptive capacity of both risk managers and residents in risky areas.

\section{References}

[1] Folke, C., Carpenter, S., Elmqvist, T., Gunderson, L., Holling, C.S., Walker, B., Bengtsson, J., Berkes, F., Colding, J., Danell, K., Falkenmark, M., Gordon, L., Kaspersson, R., Kautsky, N., Kinzig, A., Levin, S.A., Maler, K.-G., Moberg, F., Ohlsson, L., Olsson, P., Ostrom, E., Reid, W., Rockstro“ m, J., Savenije, H., Svedin, U., Resilience and sustainable development: building adaptive capacity in a world of transformations. Report for the Swedish Environmental Advisory Council 2002:1, ed. Ministry of the Environment, Stokholm, pp. 437-440, 2002.

[2] Gallopin, C.G., Linkages between vulnerability, resilience, and adaptive capacity. Global Environmental Change, 16, pp. 293-303, 2006.

[3] Mens, M.J.P., Klijin, F., de Brujin, K. M., van Beek, E., The meaning of system robustness for flood risk management, Environmental Science \& Policy, 14, pp. 1121-1131, 2011.

[4] Adger, W. N., Vulnerability, Global Environmental Change, 16, pp. 268-281, 2006. 
[5] Miller, F., Osbahr, H., Boyd, E., Thomalla, F., Sukaina, B., Ziervogel, G., Walker, B., Birkmann, J., van der Leeuw, S., Rockström, J., Hinkel, J., Downing, T., Floke, K., Nelson, D., Resilience and vulnerability: complementary or conflicting concepts? Ecology and Society 15(3):11, pp. 1-25, 2010.

[6] Thouret, J. C., D’Ercole, R., Vulnérabilité aux risques naturels en milieu humains : effets, facteurs et réponses sociales, Cahiers de Sciences Humaines, 32(2), pp. 407-422, 1996.

[7] Reghezza, M., Réflexions autour de la vulnérabilité métropolitaine: la métropole parisienne face au risque de crue centennale, doctorate thesis, Paris Nanterre-University, pp. 58-63, 2006.

[8] Reghezza, M., La vulnérabilité, un concept problématique (chapter 3), la vulnérabilité des sociétés et des territoires face aux menaces naturelles, ed. F. Leone, F. Vinet, PUM: Montpellier, pp. 35-41, 2005.

[9] Wisner B., Westgate, K., O'Keefe, P., Taking the Naturalness out of Natural Disasters, Nature, 260, pp. 566-567, 1976.

[10] Blaikie I. et al. At Risk: Natural Hazards, People's Vulnerability, eds. Routledge, London, pp. 88-123, 2003.

[11] Gunderson, L., Holling, C. S., Panarchy, Island: Washington DC, pp. 103-120.

[12] Turner, B.L., Kasperson, R. E., Matson P. A., McCarthy J. J., Corell R. W., Christensen L., Eckley N., Kasperson, J. X., Luers, A., Martello, M. L., Polsky, C., Pulsipher, A., Schiller, A., A framework for vulnerability analysis in sustainability science, Proceedings of the National Academy of Sciences of the United States of America, 100(14), pp. 8074-8079, 2003.

[13] Renn, O., Risk Governance. Coping with uncertainty in a complex world. London, Earthscan, pp. 5-11.

[14] Heitzmann, K., Sudharshan, C., Siegel, P. B., Guidelines for assessing the sources of risk and vulnerability, Social protection discussion paper series, 0218, pp. 1-60, 2002.

[15] Schelfault, K., Pannermans, B., van der Craats, I., Krywkow J., Mysiak, J., Cools J., Bringing flood resilience into practice: the FREEMAN project, Environmental Science \& policy, 14, pp. 825-833, 2005.

[16] Adger, W. N., Successful adaptation to climate change across scales, Global Environmental Change, 15, pp. 77-86, 2005.

[17] Smit, B., Wandel, J., Adaptation, adaptive capacity, and vulnerability. Global Environmental Change, 16, pp. 282-292, 2006.

[18] Nagoya-city Mayor office, http://www.city.nagoya.jp/

[19] Tominaga, A., Lessons learned from Tokai heavy rainfall, Journal of Disaster Research, 2(1), pp. 50-51, 2007.

[20] Zhai, G., Public preference and willingness to pay for flood risk reduction (chapter 4), Toward resilient society to emerging disaster risks in megacities, eds Ikeda S., Fukuzono T., Sato T., TERRAPUB and NIED, pp. 57-87, 2006.

[21] Aichi prefecture, Survey concerning evacuation in case of flood, pp. 1-63, 2011 (Japanese). 